\title{
A modified high-performance liquid chromatography method for analysis of PSP toxins in dinoflagellate, Alexandrium minutum, and shellfish from Taiwan
}

\author{
Chih Yu Chen ${ }^{\mathrm{a}, *}$, Hong Nong Chou ${ }^{\mathrm{b}}$ \\ aScience and Technology Information Center, National Science Council, 16F, No. 106 Hoping E Road, \\ Section 2, Taipei, 106 36, Taiwan, ROC \\ b Institute of Fisheries Science, National Taiwan University, Taipei, 10617, Taiwan, ROC
}

Received 15 August 2001; received in revised form 3 December 2001; accepted 18 December 2001

\begin{abstract}
Paralytic shellfish poisoning (PSP) toxins are highly toxic natural compounds produced by dinoflagellates commonly present in marine phytoplankton. Shellfish accumulate PSP toxins during toxic algal blooms. PSP poses a significant public health threat and economic loss to the shellfish industry. For this reason, many methods have been developed to analyse PSP toxins in suspected toxic shellfish samples. In our study, we simplified the sample preparation method and set up a rapid and accurate high-performance liquid chromatography (HPLC) system to detect PSP toxins in algae and shellfish on a routine basis. The toxins profile of two strains of dinoflagellate Alexandrium minutum and shellfish samples collected from southwestern locations in Taiwan has been analysed with this HPLC method. Only A. minutum and purple clam Hiatula rostrata contained PSP toxins, with GTX-1, 2, 3, 4 being the major toxins. (C) 2002 Elsevier Science Ltd. All rights reserved.
\end{abstract}

Keywords: HPLC; PSP toxins; Alexandrium minutum; Purple clams

\section{Introduction}

Paralytic shellfish poisoning (PSP) toxins are potent marine neurotoxins which block the sodium channels of the neuron cell membrane of animals (Long, Sargent, \& Hammer, 1990). In Taiwan, Alexandrium minutum is a species of dinoflagellate producing PSP toxins. GTX-1, 2, 3, 4 are the major toxins that occur in the above toxigenic species of algae and in the purple clam (Hwang et al., 1999). The purple clam Hiatula rostrata Lighttoot is known to retain and accumulate high PSP toxin levels (Chen \& Chou, 2001; Hwang, Noghchi, Ngashima, Liao, \& Hashimoto, 1987). Two food poisoning incidents due to ingesting the purple clam occurred in Tungkang, Pingtung Prefecture in 1986 and in Tungshih, Chia-yi Prefecture in 1991 (Hwang et al., 1995).

The determination of PSP toxins has been performed using the mouse assay method. The mouse assay developed

\footnotetext{
* Corresponding author. Tel.: + 886-2-273-77729; fax: 886-2-27377448 .

E-mail address: cychen@mail.stic.gov.tw (C.Y. Chen).
}

for PSP toxins monitoring has been used for toxicity determination among shellfish (AOAC, 1995). To achieve the high sensitivity and specificity in PSP toxins monitoring and to avoid the excessive killing of mice, Sullivan, Wekell, and Kentala (1985) and Nagashima, Maruyama, Noguchi, and Hashimoto (1987) developed high-performance liquid chromatography (HPLC) methods of PSP toxins analysis. The HPLC system of Oshima (1995) has become recently quite popular because it can separate all PSP toxins. However, it is not a very useful method for shellfish surveillance in monitoring situations, because it involves a time consuming solid phase extraction procedure. Furthermore, three independent isocratic runs required for the separation of C-toxins, GTX toxins and NEO/dcSTX/STX toxins make this method labour-intensive.

This paper reports a modified HPLC method to analyse PSP toxins in Taiwan. We fed purple clams with the toxic dinoflagellate $A$. minutum sufficient for the accumulated toxins to be measured clearly, and then set up a HPLC method, modified from Nagashima et al. (1987), to detect PSP toxins. Furthermore, we compared the 
HPLC system with the mouse bioassay method and the HPLC system of Oshima (1995).

\section{Materials and methods}

\subsection{Materials and culture environment}

Strain AMTK-1 of A. minutum Halim was isolated in 1986 from the Tungkang area where PSP occurred due to the ingestion of purple clams. The unialgal isolates were batch cultured in K-medium (Keller \& Guillard, 1985) and illuminated with continuous light of $60 \mu \mathrm{E}$ $\mathrm{m}^{-2} \mathrm{~s}^{-1}$ at $20-22{ }^{\circ} \mathrm{C}$. Algal cells of AMTK-1 were harvested for feeding experiments in exponential growth phase. Natural population strain AMTK-7 of A. minutum was isolated in 1997 from the Tungkang milkfish (Chanos chanos) culture pond. The AMTK-7 was collected in vertical hauls of a $20-\mu \mathrm{m}$ mesh plankton net.

The following commercial shellfish species were used for the experiment: purple clams ( $H$. rostrata), oysters (Crassostrea gigas), and the hard clam (Meretrix lusoria), which were cultured outdoor and collected in southwestern fishmarkets of Taiwan. All animal samples were kept alive during transportation from the collection sites to the laboratory.

Purple clams, which averaged $6.75 \mathrm{~cm}$ (S.E. $=0.52$, $n=100$ ) in shell length (mean tissue wet weight $=8.78 \mathrm{~g}$, S.E. $=1.08$ ), were collected from an aquaculture pond in Tungkang, Pingtung Prefecture. The clams were brought to the laboratory and placed in a 130-1 tank with filtered seawater (20 ppt salinity). Continuous aeration was carried out at $17 \pm 2{ }^{\circ} \mathrm{C}$ throughout the holding period. During the exposure period, lasting 20 days, the clams were fed with $A$. minutum at 2-day intervals and exposed each time to $5.81 \pm 0.42 \times 10^{8}$ cells.

\subsection{Assay of toxicity and $H P L C$}

Authentic PSP components (GTX1-4 mixture), prepared from $A$. minutum, were used as reference standards; the toxicity and amount were also certified by Oshima (personal communication). The method of extraction of PSP toxins was according to Chen and Chou (1998). Toxic algae samples were counted and then trapped in fiber glass, the retained algal cells were extracted with $95 \%$ acetic alcohol $(\mathrm{pH}=2)$. The extracts were concentrated and transferred to vials by means of $0.03 \mathrm{~N}$ acetic acid, defatted with chloroform, and the aqueous layer was ultrafiltered (10,000 MW cut-off) by centrifugation at $3000 \mathrm{rpm}$. Purple clam tissues were homogenized with $15 \mathrm{ml} 0.1 \mathrm{M} \mathrm{HCl}$, the extracts were defatted and ultrafiltered by centrifugation. Subsequently, $10 \mu \mathrm{l}$ of the supernatant of algae and shellfish from centrifugation was injected into the HPLC with a post-column reaction system (modified from Nagashima et al., 1987). All solvents used were HPLC grade. Other chemicals were analytical grade. Water used for HPLC was purified with a Millipore-QRG Ultra Pure Water System (Millipore, Milford, USA). HPLC was run by a combination of Hitachi L-6200 Intelligent pump and L6000 Reagent pump (Tokyo). Fig. 1 shows our HPLC system for PSP toxins analysis. The $\mathrm{pH}$ of mobile phase was then adjusted to 7.0 with $0.05 \mathrm{M} \mathrm{K}_{2} \mathrm{HPO}_{4}$ and 0.05

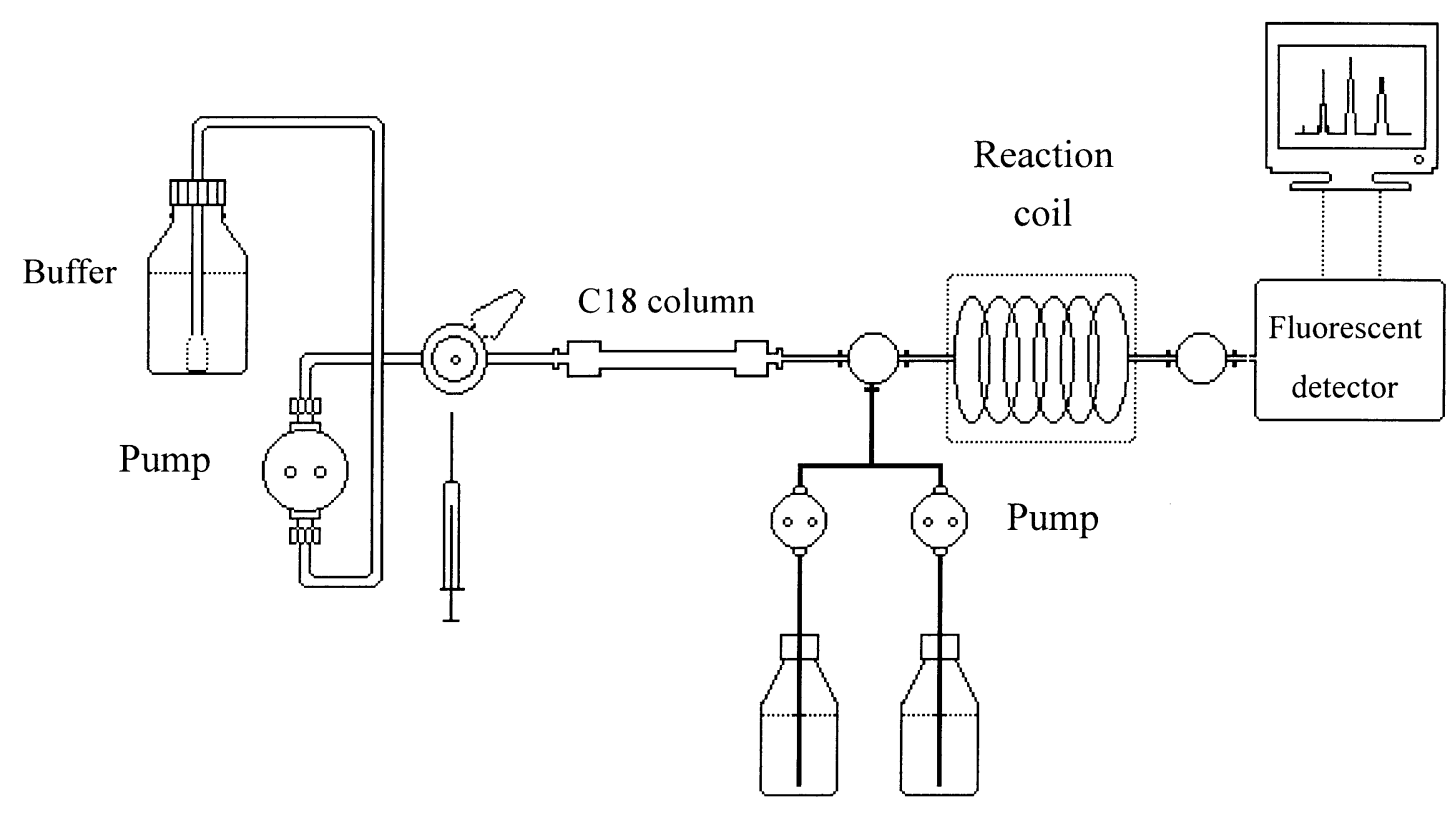

(A)

(B)

Fig. 1. High-performance liquid chromatography (HPLC) system for paralytic shellfish poisoning (PSP) toxins analysis. 
$\mathrm{M} \mathrm{KH}{ }_{2} \mathrm{PO}_{4}$, phosphate buffer contained $2 \mathrm{mM}$ heptanesulfonic acid (HSA). The column used was a $5 \mu \mathrm{m}$, $250 \times 4.6 \mathrm{~mm}$ Cosmosil 5C18-AR column (Nacalai Tesque Inc, Kyoto) at a flow rate of $0.8 \mathrm{ml} / \mathrm{min}$. Fluorescent PSP toxin derivatives were detected using a Hitachi F-1000 spectrophotometer with excitation at $336 \mathrm{~nm}$ and emission at $390 \mathrm{~nm}$. There are two solutions used for post-column derivatization, which contained (A) periodic acid solution $(0.05 \mathrm{M})$ and $(\mathrm{B})$ alkaline solution $(0.2 \mathrm{~N} \mathrm{KOH}$ plus $1 \mathrm{M}$ ammonium formate in $50 \%$ formamide). Oshima's method (1995) is summarized in Table 1.

\subsection{Mouse bioassay}

The mouse bioassay was performed according to the method described by Chou (1999). Mice of ICR strains $(19-21 \mathrm{~g})$ used in the toxicity assay were purchased from the Animal Laboratory of National Taiwan University Hospital. Purple clam extracts of 20 samples with various known toxicity levels by HPLC analysis were diluted and injected intraperitoneally into a group of four mice. The lethal potency was calculated as the time required to kill the mice and was expressed in mouse units (MU) according to the formulation defined by Chou (1999). Sample toxicities obtained from both mouse bioassay and HPLC analysis were compared with each other.

\subsection{Calculation}

The conversion of peak areas of HPLC-resolved toxins into mouse units was according to the following formula: Toxicity $\quad(\mathrm{MU} / \mathrm{ml})=\left(19.7 \mathrm{~A}_{1}+0.57 \mathrm{~A}_{2}+1.61 \mathrm{~A}_{3}+8.11\right.$ -
$\left.\mathrm{A}_{4}\right) \times 10^{-6}$, where $\mathrm{MU}=1$ mouse unit and $\mathrm{A}_{1}, \mathrm{~A}_{2}, \mathrm{~A}_{3}, \mathrm{~A}_{4}$ represented the peak areas of the resolved toxins, GTX$1,2,3$ and 4, respectively. The use of the formula was justified on the basis that there were no resolved peaks other than those corresponding to the earlier four toxins in the tested material. The calibration factors for each toxin were adopted from mouse assays of partially purified toxin mixtures with the reported specific toxicity (Genenah \& Shimizu, 1981) and the reported specific fluorescent response (Sullivan et al., 1985). This provides a way to convert the HPLC data to the generally accepted mouse toxicity units as STX equivalents (AOAC, 1995). In our case it was observed that $1 \mathrm{MU}$ (ICR strain, male, $20 \mathrm{~g}$ ) was equivalent to $0.259 \mu \mathrm{g} / \mathrm{ml}$ STX by the calibration procedure suggested by the AOAC (Chou, 1999). According to the earlier formula and the corresponding mouse responses to each toxin, the specific amount $(\mu \mathrm{mol})$ of each individual toxin could thus be calculated from its peak area. Correlation factors for each toxin were $1.2 \times 10^{-10}, 7.2 \times 10^{-12}$, $7.2 \times 10^{-12}$, and $1.2 \times 10^{-10}$ for GTX-1, 2, 3 and 4 , respectively.

\section{Results and discussion}

Twenty purple clam extracts of different PSP toxin amount known from HPLC analysis were also analysed for toxicity by mouse assay. MU data converted from HPLC peak areas were compared with data obtained from the mouse assay for each toxic sample and showed a slight overestimate of toxicity (Fig. 2). The possible reason of toxicity overestimate might be the higher sensitivity of HPLC and dilution factor of HPLC values

Table 1

HPLC conditions used for the analysis of PSP toxins according to Oshima (1995) ${ }^{\mathrm{a}}$

\begin{tabular}{ll}
\hline Parameter & Condition or description \\
\hline Column & Reversed-phase, C8-bonded silica gel, Develosil C8-5 or Inertsil C8-5, (4.6 mm i.d. $\times 150 \mathrm{~mm} 1)$ \\
$\begin{array}{l}\text { Mobile phase } \\
\text { Flow rate }\end{array}$ & $0.8 \mathrm{ml} / \mathrm{min}$ \\
For GTX1-4 & Sodium 1-heptanesulfonate $(2 \mathrm{mM})$ in $10 \mathrm{mM}$ ammonium phosphate, $\mathrm{pH} 7.1$ \\
& \\
Oxidizing reagent & $0.4 \mathrm{ml} / \mathrm{min}$ \\
Flow rate & Periodic acid $(7 \mathrm{mM})$ in $50 \mathrm{mM}$ potassium phosphate buffer, $\mathrm{pH} 9.0$ \\
Composition & $10 \mathrm{~m} \mathrm{Teflon}$ tubing $\left(0.5 \mathrm{~mm}\right.$ i.d.) at $85^{\circ} \mathrm{C}$ in a drying oven \\
Reaction & \\
Acidifying reagent & $0.4 \mathrm{ml} / \mathrm{min}$ \\
Flow rate & $0.5 \mathrm{M} \mathrm{acetic} \mathrm{acid}$ \\
Composition & \\
Detection & $330 \mathrm{~nm}$ \\
Excitation & $390 \mathrm{~nm}$ \\
Emission &
\end{tabular}

a HPLC, high-performance liquid chromatography; PSP, Paralytic shellfish poisoning. 
used to convert to mouse assay values. The mouse assay method often underestimates toxin contents in lowtoxicity shellfish (Oshima, 1995). A regression line, $Y=0.4987 X+0.3286\left(R^{2}=0.8764\right)$ was plotted on all MU data in Fig. 2 to show a good correlation between these two methods.

A comparison between the toxin profile obtained from the HPLC system used in analysis and Oshima's system, showed that our system does not need the time consuming solid phase extraction procedure and has shorter analysis time. Furthermore, the numbers of theoretical plate of two HPLC systems are similar (Table 2). Both systems show good separations of GTX1, GTX2, GTX3, and GTX4 (Fig. 3). The detection limit of Oshima's system is $1.7 \sim 17 \times 10^{-3} \mathrm{MU} / \mathrm{ml}$ (GTX-1, 2, 3 and 4, respectively) compared with our system's detection limit of $13 \times 10^{-3} \mathrm{MU} / \mathrm{ml}$ (GTX-1-4 standard mixture). This corresponds to a detection limit of $0.2 \mathrm{MU}\left(5.18 \times 10^{-2} \mu \mathrm{g}\right.$ STX equiv. $) / \mathrm{g}$ shellfish meat

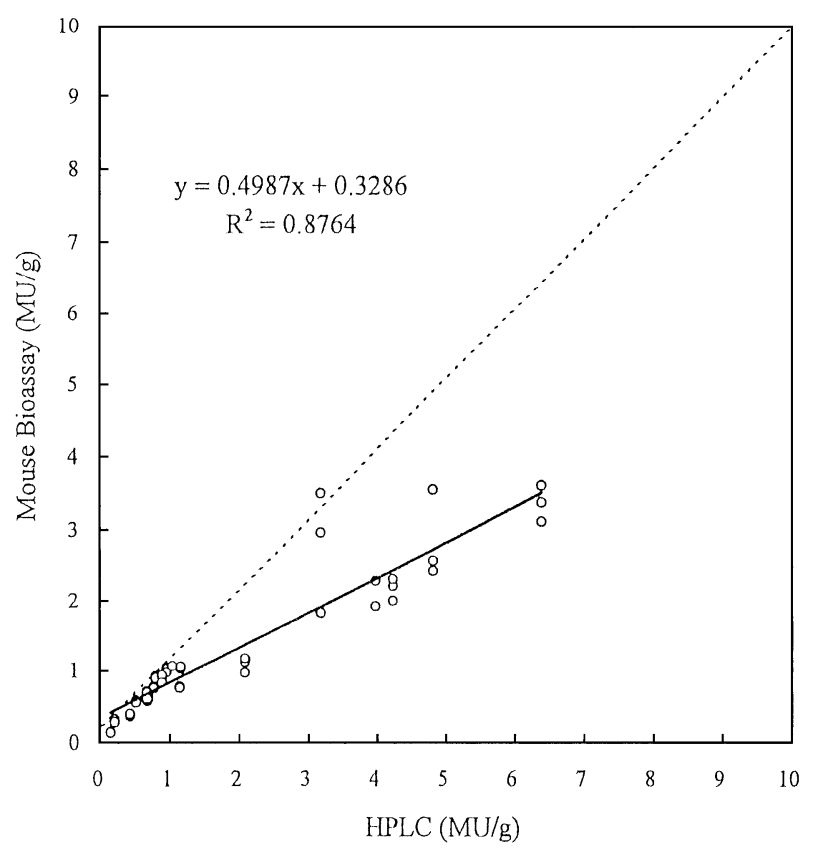

Fig. 2. Correlation between mouse unit (MU) data converted from high-performance liquid chromatography (HPLC) analysis and mouse assay. The dotted line represents good correlation between the two assay methods. for our HPLC system. Our HPLC column produced reproducible results after the analysis of 1000 samples without prior clean-up process. Such a HPLC system is suitable for a routine PSP toxins (GTX-1-4) survey in Taiwan. The HPLC system of Oshima is suitable for analyzing the toxigenic algae or shellfish that contains many analogues of PSP toxins, such as C-toxins, NEO/ dcSTX/STX toxins.

A comparison of HPLC methods based on ion-pair elution of PSP toxins reveal some striking differences between the methods proposed (Franco \& FernandezVila, 1993; Lawrence, Wong, \& Menard, 1996; Oshima, 1995; Sullivan et al., 1985; Yu, Hummert, Luckas, Qian,
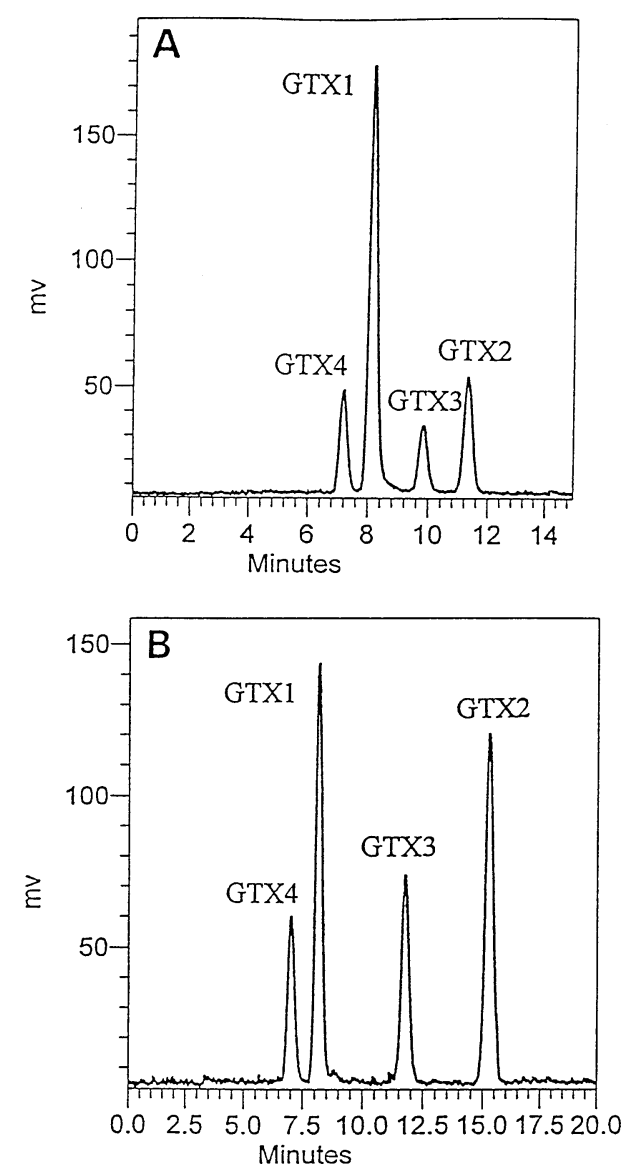

Fig. 3. High-performance liquid chromatograms (HPLC) of GTX-1-4 standard mixture. (A) experimental system (B) Oshima (1995).

Table 2

Comparison of HPLC a systems with that of Oshima (1995) and conditions used in this analysis

\begin{tabular}{|c|c|c|c|c|c|c|c|c|c|c|}
\hline & \multirow{2}{*}{$\begin{array}{l}\text { Solid phase } \\
\text { extraction }\end{array}$} & \multirow{2}{*}{$\begin{array}{l}\text { Separation } \\
\text { time (min) }\end{array}$} & \multicolumn{3}{|c|}{ Resolution (Rs) } & \multicolumn{5}{|c|}{ No. of theoretical plate $(\mathrm{N})$} \\
\hline & & & $\begin{array}{l}\text { Rs } \\
\text { (GTX4\&1) }\end{array}$ & $\begin{array}{l}\text { Rs } \\
\text { (GTX1\&3) }\end{array}$ & $\begin{array}{l}\text { Rs } \\
\text { (GTX3\&2) }\end{array}$ & $\mathrm{N}_{\mathrm{GTX} 4}$ & $\mathrm{~N}_{\mathrm{GTX} 1}$ & $\mathrm{~N}_{\mathrm{GTX} 3}$ & $\mathrm{~N}_{\mathrm{GTX} 2}$ & $\mathrm{~N}_{\mathrm{AVG}}$ \\
\hline Our HPLC system & No & 15 & 0.63 & 1.24 & 1.29 & 401 & 478 & 932 & 1950 & 940 \\
\hline Oshima's HPLC system & Yes & 20 & 0.87 & 2.03 & 1.76 & 271 & 1104 & 329 & 1863 & 892 \\
\hline
\end{tabular}

a HPLC, high-performance liquid chromatography. 


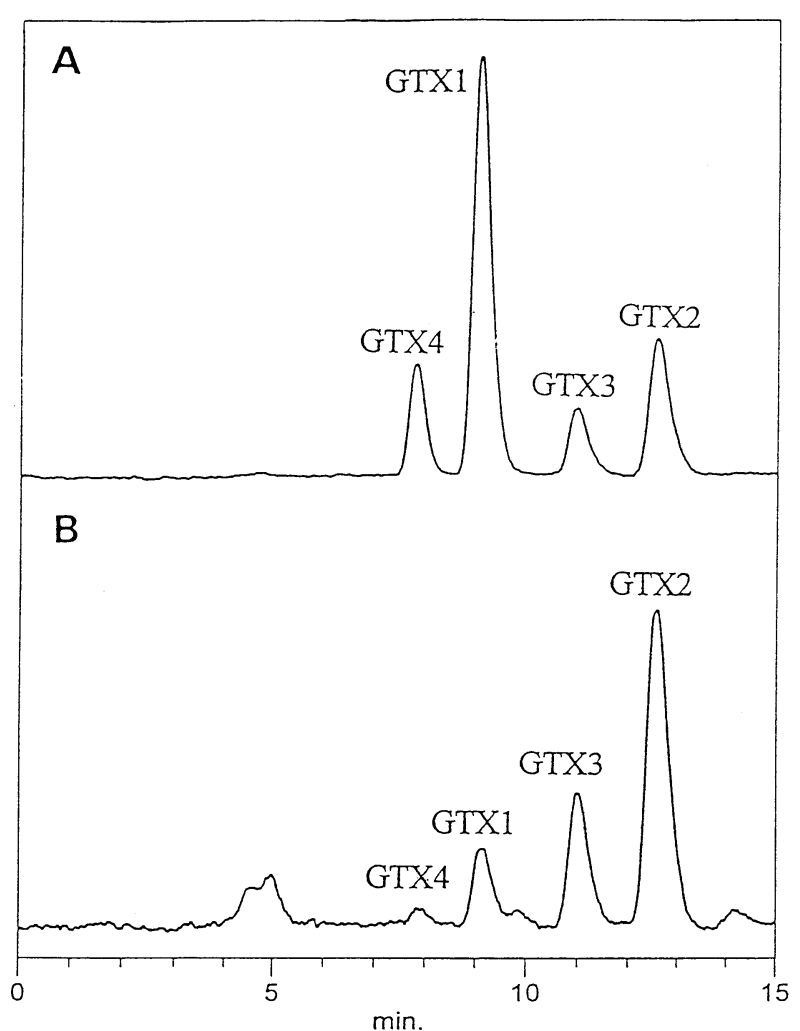

Fig. 4. High-performance liquid chromatograms (HPLC) of paralytic shellfish poisoning (PSP) toxin profiles of (A) laboratory cultured purple clams (B) purple clams collected from fishmarkets.

Li, \& Zhou, 1998). These methods show that the buffer concentration used does not have a large influence on the separation of PSP toxins, but ensures high stability of the chromatography irrespective of the injection of extracts obtained from different sample materials.

Fig. 4 shows the HPLC chromatograms of purple clams fed toxic algae in the laboratory and purple clams collected from Tungkang fishmarkets. Fig. 5 shows the HPLC chromatograms of $A$. minutum extracts from the laboratory stock culture AMTK-1 and the natural populations AMTK-7 from milkfish culture pond. Figs. 4 and 5 shows that the percentage of GTX3 and GTX2 in laboratory cultured algae and purple clams was lower than that of fishpond collected algae and outdoor cultured purple clam. The result of the toxin profiles from fishpond collected algae and outdoor cultured purple clams are similar with that of previous report (Hwang, Tsai, Cheng, \& Jeng, 1992).

Negative results were obtained for most of oysters (Crassostrea gigas) and hard clams (M. lusoria), which indicates that PSP toxin contamination is not common in the southwestern part of Taiwan. Only the Taiwanese purple clams ( $H$. rostrata) were ever confirmed to be contaminated with PSP toxins. Compared with the PSP toxin level stipulated by most countries $(80 \mu \mathrm{g}$ STX equiv./100 g shellfish meat), the levels found in most of
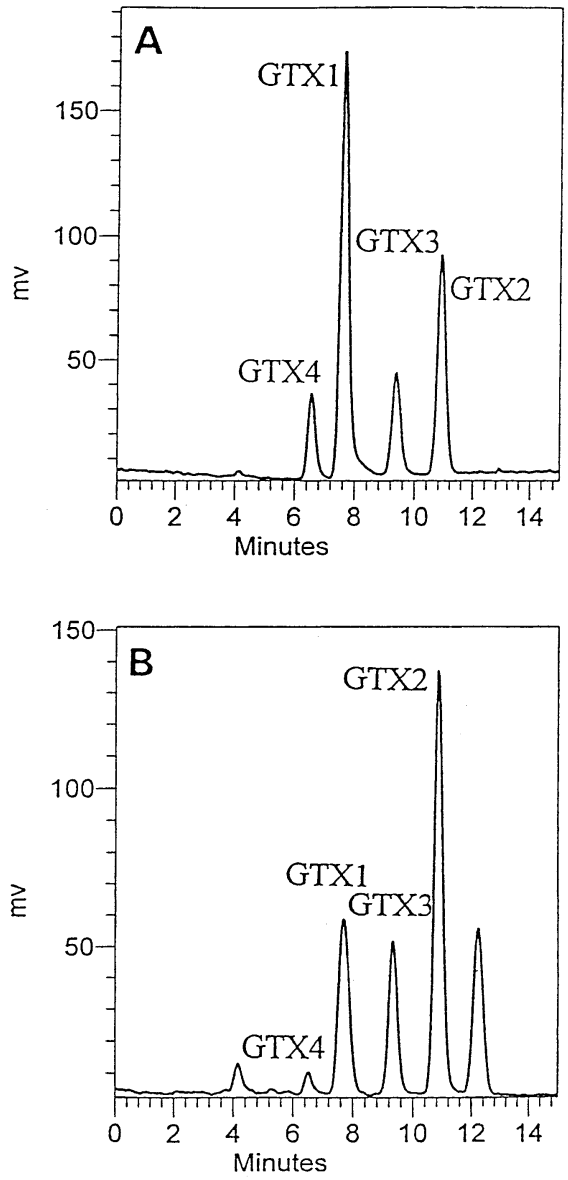

Fig. 5. High-performance liquid chromatograms (HPLC) of paralytic shellfish poisoning (PSP) toxin profiles of Alexandrium minutum. (A) laboratory cultured AMTK-1 (B) milkfish culture pond collected AMTK-7.

the samples were less than this allowable amount. Recently, a massive mortality of milkfish and other fish species occurred in southwestern area of Taiwan due to A. minutum blooming in the culture ponds (Chou, 1999). We used our HPLC system to analyse the milkfish samples. The stomach and intestine tissue of milkfish were contaminated with PSP toxins (GTX-1-4), but the gill, liver, muscle tissues, and the blood was not contaminated (data not shown). The results indicate that we should not only care about the food poisoning incidents from purple clams but pay more attention to the potential hazard of fish contaminated with $A$. minutum.

\section{Conclusion}

The modified HPLC system could qualitatively and quantitatively analyse the PSP toxins in algae and shellfish from Taiwan. This method is time-saving and avoids animal sacrifice in the bioassay method. 


\section{Acknowledgements}

This work was supported by grants from the National Science Council (Grant No. NSC86-2113-M002-014) awarded to H. N. Chou.

\section{References}

AOAC. (1995). Paralytic shellfish poisons biological method final action. In W. Horwitz (Ed.), Official Methods of the Association of Official Analytical Chemists, (15th ed.) (pp. 21-22). Washington, DC: Association of Official Analytical Chemists.

Chen, C. Y., \& Chou, H. N. (1998). Transmission of the paralytic shellfish poisoning toxins, from dinoflagellate to gastropod. Toxicon, 36, 515-522.

Chen, C. Y., \& Chou, H. N. (2001). Accumulation and depuration of paralytic shellfish poisoning toxins by purple clam Hiatula rostrata Lighttoot. Toxicon, 39, 1029-1034.

Chou, H. N. (1999). Paralytic shellfish poisoning toxins. In: N. Chou (Ed.) Manual on microalgal toxin detection in seafood products. DOH, Taipei, pp. 23-44.

Franco, J. M., \& Fernandez-Vila, P. (1993). Separation of paralytic shellfish toxins by reversed phase high performance liquid chromatography, with postcolumn reaction and fluorimetric detection. Chromatographia, 35, 9-12.

Genenah, A. A., \& Shimizu, Y. (1981). Specific toxicity of paralytic shellfish poisons. Journal of Agricultural Food Chemistry, 29, 12891291.

Hwang, D. F., Noguchi, T., Nagashima, Y., Liao, I. C., \& Hashimoto, K. (1987). Occurrence of paralytic shellfish poison in the purple clam Soletellina diphos (Bivalve). Nippon Suisan Gakkaishi, 53, 623626 .
Hwang, D. F., Tsai, Y. H., Cheng, C. A., \& Jeng, S. S. (1992). Comparison of paralytic toxins in aquaculture of purple clam in Taiwan. Toxicon, 30, 669-672.

Hwang, D. F., Tsai, Y. H., Cheng, C. A., Liao, I. C., Jeng, S. S., Noguchi, T., \& Hashimoto, K. (1995). Two food poisoning incidents due to ingesting the purple clam occurred in Taiwan. Journal of Natural Toxins, 4, 173-179.

Hwang, D. F., Tsai, Y. H., Liao, H. J., Matsuoka, K., Noguchi, T., \& Jeng, S. S. (1999). Toxins of the dinoflagellate Alexandrium minutum Halim from the coastal waters and aquaculture ponds in southern Taiwan. Fisheries Science, 65, 171-172.

Keller, M. D., \& Guillard, R. R. L. (1985). Factors significant to marine dinoflagellate culture. In D. M. Anderson, A. W. White, \& D. G. Baden (Eds.), Toxic dinoflagellate (pp. 113-116). New York : Elsevier.

Lawrence, J. F., Wong, B., \& Menard, C. (1996). Determination of decarbamoyl saxitoxin and its analogues in shellfish by prechromatographic oxidation and liquid chromatography with fluorescence detection. Journal of AOAC International, 79, 1111-1115.

Long, R. R., Sargent, J. C., \& Hammer, K. (1990). Paralytic shellfish poisoning: a case report and serial electrophysiologic observations. Neurology, 40, 1310-1311.

Nagashima, Y., Maruyama, J., Noguchi, T., \& Hashimoto, K. (1987). Analysis of paralytic shellfish poison and tetrodotoxin by ion-pairing high performance liquid chromatography. Nippon Suisan Gakkaishi, 53, 819-823.

Oshima, Y. (1995). Postcolumn derivatization liquid chromotographic method for paralytic shellfish toxins. Journal of AOAC International, 78, 528-532.

Sullivan, J. J., Wekell, M. M., \& Kentala, L. L. (1985). Application of HPLC for the determination of PSP toxins in shellfish. Journal of Food Science, 50, 26-29.

Yu, R. C., Hummert, C., Luckas, B., Qian, P. Y., Li, J., \& Zhou, M. J. (1998). A modified HPLC method for analysis of PSP toxins in algae and shellfish from China. Chromatographoa, 48, 671-676. 